\title{
Discrimination Concerns and Expectations as Explanations for Gendered Socialization in African American Families
}

\author{
Fatima Varner \\ University of Michigan
}

\author{
Jelani Mandara \\ Northwestern University
}

\begin{abstract}
Discrimination concerns and parental expectations were examined as mediators of the relations between gender and parenting practices among 796 African American mothers of 11- to 14-year-olds from the Maryland Adolescent Development in Context Study. Mothers of sons had more concerns about racial discrimination impacting their adolescents' future, whereas mothers of daughters had more gender discrimination concerns. Racial discrimination concerns, but not gender discrimination concerns, were related to lower maternal academic and behavioral expectations. Maternal expectations were related to mothers' responsiveness, rule enforcement, monitoring, and parent-adolescent conflict. The relations between gender and parenting practices were partially explained through mothers' racial discrimination concerns and expectations. These findings demonstrate the importance of contextual factors on African American family processes.
\end{abstract}

Although adolescent females outperform adolescent males in academic achievement and are less likely to engage in high-risk behaviors across all ethnic groups, the gender gaps are especially large among African Americans. African American females outperform African American males at every stage of the educational pipeline, with females having higher grade point averages, high school graduation rates, and rates of college attendance and graduation than males (Saunders, Davis, Williams, \& Williams, 2004). These gaps have grown over time. For instance, in 2005 African American women earned $66 \%$ of all bachelor's degrees awarded to African Americans compared to 1976 when African American women earned 57\% of bachelor's degrees (Snyder \& Dillow, 2007). African American girls also have higher educational expectations and academic self-efficacy than boys (Saunders et al., 2004; Wood, Kaplan, \& Mcloyd, 2007). These gender differences in education have significant implications for employment opportunities, income, and family life, particularly in a knowledge-based economy in which the most competitive workers have high level skills in information and technology (Organisation for Econonomic Cooperation and Development, 2005).

We are thankful to Lindsay Chase-Lansdale and Emily Durbin for their feedback on earlier versions of this manuscript.

Correspondence concerning this article should be addressed to Fatima Varner, Center for the Study of Black Youth in Context, University of Michigan School of Education, 610 E. University Ave, Ann Arbor, MI 48109. Electronic mail may be sent to fvarner@umich.edu.
Even though there are a number of social factors that contribute to these gender differences, recent studies have found that one contributor to these gender differences in achievement and behavior is that African American males and females are socialized differently (Mandara, Varner, \& Richman, 2010). In particular, some studies have found that parenting differences account for gender differences in academic expectations (Wood et al., 2007), test scores (Mandara et al., 2010), and externalizing behavior (Bean, Barber, \& Crane, 2006).

One critical limitation of this line of research is that little is known about why African American mothers differentially socialize their sons and daughters. Several authors have theorized about the likely causes (Hill, 2002; Mandara et al., 2010; Wood et al., 2007), but no empirical studies have been conducted. Understanding why maternal socialization differs by adolescent gender can help inform community, school, and family practices and interventions designed to address gender disparities in academic achievement, and increase knowledge of how context influences parental beliefs and practices. We argue that African American mothers expect their sons to face greater racial discrimination. Consequently, we expect that these fears of discrimination will lower mothers' educational expectations of their sons, which will

(C) 2012 The Authors

Child Development (C) 2012 Society for Research in Child Development, Inc. All rights reserved. 0009-3920/2013/8403-0010

DOI: $10.1111 /$ cdev.12021 
lead them to socialize their sons in a less academically focused manner than they do their daughters. Thus, the primary purpose of this study was to test this model in a large sample of African American adolescents and their mothers. Because of the history and prevalence of gender discrimination, we also examined the role of mothers' gender discrimination concerns.

\section{Theoretical Framework}

We argue that the primary causes of differential socialization of males and females in African American families are rooted in the broader social context. As articulated by the integrative model of minority child development (Garcia Coll et al., 1996), the environments in which ethnic minority children develop are influenced by racism, discrimination, and prejudice due to their social position in the United States. African American children and adolescents develop in settings in which there are many stereotypes and biases about their academic ability, cognitive skills, and behaviors. Although overt discrimination is at lower levels than in past decades, there is much evidence that African American adolescents experience discrimination in schools, classrooms, and neighborhoods (Chavous, Rivas-Drake, Smalls, Griffin, \& Cogburn, 2008; Swanson, Cunningham, \& Spencer, 2003). Gender plays an important role as well among African American adolescents as African American males often report experiencing more discrimination than females (Seaton, Caldwell, Sellers, \& Jackson, 2008).
This devaluation of African American males may impact parenting as parents respond to their children's experiences and contexts.

In addition, as suggested by the phenomenological variant of ecological systems theory (Spencer, Dupree, \& Hartmann, 1997), one's appraisals of the social context and experiences have significance for identity and behavior. As members of a stigmatized group, minority parents' perceptions of the racial climate in their children's environments may impact parents' goals, beliefs, and child-rearing practices. For instance, many African American parents give messages to their children to prepare them for racial barriers that they may encounter and they tend to provide boys with more of these messages (Bowman \& Howard, 1985; Thomas \& Stevenson, 2009). This gender difference in racial socialization messages suggests that parents tailor their parenting based on their perceptions of their adolescents' environments and needs. Less studied is how other parenting practices and beliefs are influenced by parents' concerns about the exposure and effects of discrimination on their children. Because parents' appraisals may significantly influence their parenting, in this study we examine the influence of parents' concerns about racial discrimination and gender discrimination for their adolescents on parents' expectations and practices.

As shown in Figure 1, the theoretical model takes into consideration how mothers' perceptions of the social context can contribute to differential socialization in African American families. Overall, it proposes that African American adolescents'

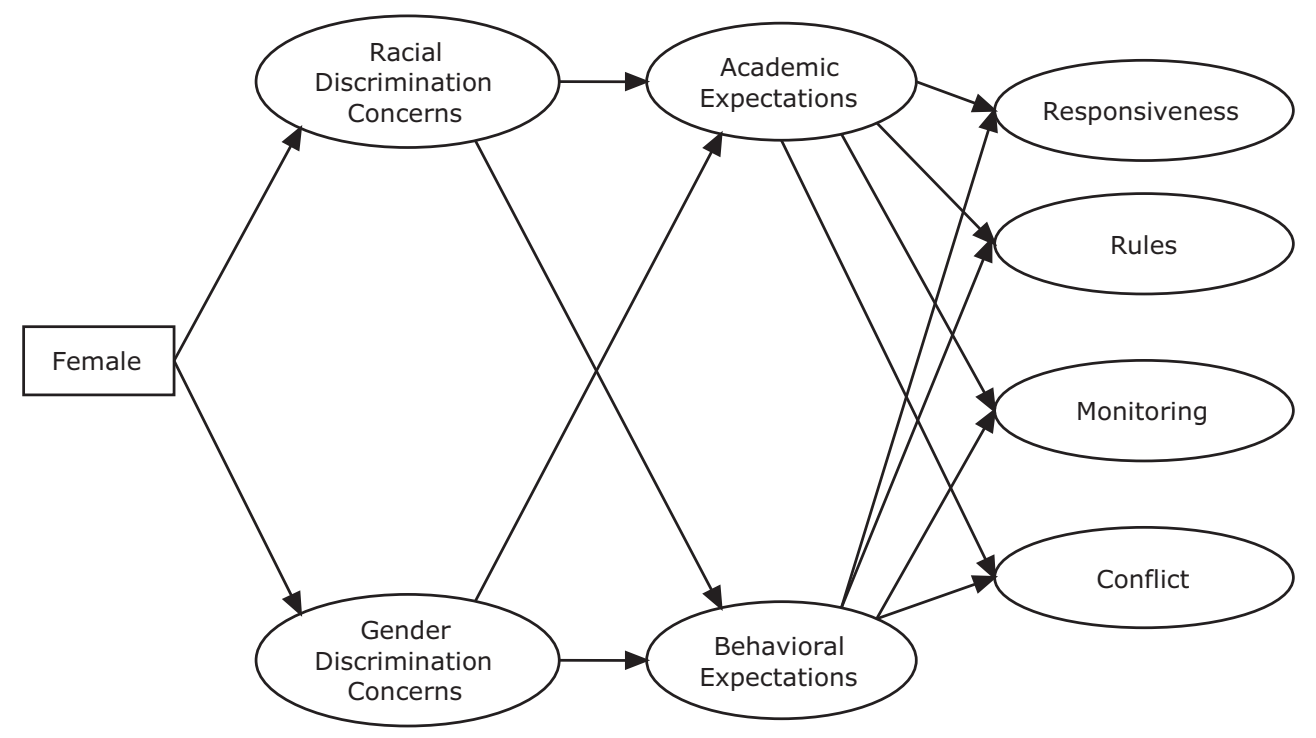

Figure 1. Conceptual model of gender, discrimination concerns, and parental expectations on parenting practices.

Note. Family income, maternal age, maternal education, and adolescents' fifth-grade test scores are controlled in the model. 
gender influences their mothers' concerns about how much racial and gender discrimination will be obstacles to their future long-term success. In turn, these concerns influence mothers' expectations of their adolescents' academic success and likelihood of engaging in risky behaviors. These expectations then have effects on mothers' parenting practices. In particular, we expected mothers with higher academic expectations and lower risky behavior expectations for their adolescents to be more responsive and demanding, as well as report less conflict with their adolescents. The underlying tenants of this model are discussed in more detail in the following sections.

\section{Differential Socialization of Males and Females in African American Families}

Although few studies on African American adolescents have directly focused on differential socialization, there are numerous findings of gender differences in parenting. The domains of behavioral control, parent-adolescent conflict, and responsiveness have been often studied. Parental monitoring has been found to protect both male and female African American adolescents from poor outcomes including delinquency (Richards, Miller, O'Donnell, Wasserman, \& Colder, 2004) and lower academic achievement (Mandara, 2006). Several studies have found that African American girls are monitored more (Pettit, Laird, Dodge, Bates, \& Criss, 2001) even though boys may face more physical dangers particularly in low-income, urban neighborhoods (Richards et al., 2004). In addition to monitoring, parents often enforce more rules with girls. For instance, middle-class African American mothers have been found to give girls more rules regarding their friendships (Smetana, 2000).

There have been mixed findings regarding the role of adolescent gender in parent-adolescent conflict in African American families. Smetana and Gaines (1999) found that middle-class mothers of boys had more conflict than middle-income mothers of girls or upper-income mothers of boys regarding schoolwork and academic achievement. Upper-income families reported using more punishment with boys because of concerns about their greater psychosocial risks due to discrimination. Other studies suggest that families with girls have more conflict as African American mothers tend to be in closer relationships with more behavioral control with their daughters than sons (Cauce et al., 1996). In addition, boys tend to be granted more autonomy and engage in more reasoning about conflicts as issues over personal jurisdiction (Smetana \& Gaines, 1999). Another important parenting dimension for adolescent academic achievement is responsiveness. However, unlike a common notion that suggests that mothers may be more demanding of their daughters but warmer with their sons (Cauce et al., 1996), most studies find that girls and boys report the same levels of maternal warmth, or the girls report higher levels. For instance, Mandara and Pikes (2008) surveyed African American high school students and found that the girls reported significantly higher levels of behavioral control from their mothers (e.g., maternal strictness, having to follow rules), but they were the same as the boys on maternal support and even psychological control.

Virtually all of the studies that have directly examined mothers' differential treatment of African American adolescents found that mothers are more demanding of daughters than they are of sons. Hill and Zimmerman (1995) observed and interviewed a small sample of low-income African American mothers whose children had sickle cell anemia. The mothers of sons were more protective and more likely to consider their child as fragile compared to mothers of daughters. Mothers of girls were more demanding and expected their daughters to have as normal a life as they could. In a similar study of 35 African American parents of various socioeconomic status (SES) backgrounds, Hill (2002) concluded that mothers of daughters emphasized self-reliance and assertiveness and generally had higher expectations for their children compared to mothers of sons. Hill argued that mothers thought African American females tended to be more striving than African American males. Sharp and Ispa (2009) conducted a similar qualitative study with inner-city single African American mothers that came to similar conclusions. They found that even mothers of infants and young children had different goals for sons and daughters. Mothers of daughters attempted to promote independence and strength in their daughters, whereas mothers of sons had childrearing goals that were more fear based. In general, the mothers tended to have more approach goals for their daughters and avoidance goals for their sons.

Similar results have also been found in larger studies. For instance, in a recent observational study, African American mothers of young boys were found to be less sensitive and higher in negative control than mothers of girls during an interactive task (Tamis-Lemonda, Briggs, McClowry, \& Snow, 2009). These differences also partially mediated boys' lower responsiveness and task 
involvement. The authors argued that mothers may treat sons differently because they expect more problem behaviors from boys. The boys in the study were rated by their mothers as having more behavior problems than the girls and also complained more, were less communicative, and less persistent during the interactive task and clean-up. More behavioral problems among boys have also been found in other studies examining gender differences and may relate to differences in parenting practices by gender (Bettencourt \& Miller, 1996). Parents may engage in more behavioral control strategies with children who present more challenging behavior.

In the largest study to date, researchers used 1,500 families and found that the daughters of African American single mothers had significantly more household chores, greater parental monitoring, and greater freedom to make decisions compared to boys of single mothers (Mandara et al., 2010). Observers also rated the homes of girls as being more cognitively stimulating than the homes of boys. The gender differences in achievement and some of the differences in externalizing behavior were accounted for by these different socialization experiences. Thus, it does not seem that mothers are warmer with sons than they are with daughters, but there is a consistent trend throughout the studies that shows that mothers are more demanding of their girls than their sons. What is not clear is why this differential socialization occurs.

\section{Effects of Discrimination Concerns on Parental Expectations}

Most of the researchers who have examined differential socialization of males and females in African American families have theorized that one contributor is parental concerns about how discrimination will influence their children's life chances (Hill, 2002; Wood et al., 2007). Due to the prevalence of racial discrimination against African American boys, parents of African American boys may be more concerned about the effects of racial discrimination on their children's future. While both African American adolescent males and females experience racial discrimination (Seaton et al., 2008), African American males have been particularly socially devalued in the academic and professional domains. For instance, adolescents across ethnicities have rated African American boys as the least likely to do well in academics (Hudley \& Graham, 2001) and teachers are more likely to view African American boys as lazy, aggressive, and less academically inclined than boys of other ethnicities (Neal, McCray, Webb-Johnson, \& Bridgest, 2003; Thomas \& Stevenson, 2009). Researchers have found that experiences of racial discrimination in school contexts can negatively influence the school performance, psychological well-being, and coping strategies of African American boys (Stevenson, 1997; Swanson et al., 2003). These findings underscore prevalent stereotypes and beliefs regarding African American boys' intellectual capabilities and racial barriers to their academic success and wellbeing. Studies also suggest that parents respond to their children's environments. Parents of African American boys have been found to engage in more parental monitoring in high-risk neighborhoods (Cunningham, Swanson, Spencer, \& Dupree, 2003) and give more messages about coping with antagonism to boys who have experienced discrimination (Stevenson, McNeil, Herrero-Taylor, \& Davis, 2005).

Concerns about the effects of discrimination may contribute to lower expectations of educational and professional success and higher expectations of behavioral problems. Although there have not been studies examining the role of discrimination concerns on parents' expectations, other studies have found a negative relation between perceptions of racial discrimination and adolescents' expectations. Perceptions of racial discrimination have been found to directly lower adolescents' expectations and lead to academic disengagement (Burchinal, Roberts, Zeisel, \& Rowley, 2008). Irving and Hudley (2005) found an inverse relation between cultural mistrust, the tendency for African Americans to distrust European Americans in institutional, personal, or social contexts, and outcome expectations. Male African American adolescents who perceived barriers to be racially motivated had lower expectations for academic success. Negative relations have also been observed between adolescents' career aspirations and perceived barriers, as well as between perceived barriers and family support for their aspirations (Hill, Ramirez, \& Dumka, 2003).

Gender discrimination concerns were also examined because the social location of both African American female and male adolescents can make them targets of gender discrimination. Research suggests that the majority of women, regardless of race, experience discrimination based on their gender at some point in their lifetimes and many report recent experiences (Klonoff \& Landrine, 1995; Klonoff, Landrine, \& Campbell, 2000). Women of color also have reported experiencing more sexism than European American women (Klonoff \& Landrine, 
1995). These personal experiences of discrimination may cause mothers to be more concerned about gender discrimination for their daughters. In addition, in qualitative studies, African American mothers and fathers have mentioned that they are concerned about the influence of gender on their daughters' lives and that they want to teach their daughters to be independent and successful professionally (Hill, 2002). These findings suggest that African American parents consider the role of gender in their children's future and may be concerned about the role of gender discrimination on their daughters' lives.

African American males may also experience gender discrimination. Social dominance theory suggests that males in lower status groups are greater targets of bias than females because they are perceived as threats to the hierarchy (Sidanius, Pratto, Laar, \& Levin, 2004). Studies have indicated that African American males are vulnerable due to stigmatization and stereotypes of African American males as aggressive, hypersexual, and prone to criminality (Thomas \& Stevenson, 2009). One study found African American male adolescents to report more gender discrimination experiences than African American female adolescents, even though they reported similar levels of racial discrimination experiences (Cogburn, Chavous, \& Griffin, 2011). This finding suggests the possibility that African American parents may also be concerned about their sons being targets of gender discrimination. Due to the lack of research examining the gender discrimination experiences of African American boys and the history of gender discrimination being conceptualized as targeting females, it remains unclear whether parents will consider some of the discrimination experiences of African American boys as gender discrimination rather than racial discrimination. Ethnic prominence theory suggests that when evaluating discriminatory experiences, racial and ethnic minorities are more likely to focus on race rather than gender (Levin, Sinclair, Veniegas, \& Taylor, 2002), which suggests that parents will have more racial discrimination concerns than gender discrimination concerns. Because gender discrimination has been more associated with female targets, we predict that mothers will be more concerned about gender discrimination concerns for their daughters than sons. We also expect that racial discrimination concerns will have stronger relations than gender discrimination with expectations and parenting practices.

There also could be an interaction between gender and racial discrimination concerns. The social location of African American females and African American males can make them both targets of racial and gender discrimination. Parents who have concerns about both racial and gender discrimination may differ in their socialization practices from parents who have concerns in only one area of discrimination.

\section{Effects of Parental Expectations on Parenting}

A long history of research has examined the nature and effects of one's expectations on his or her future behavior. In general, many studies have found that experimentally manipulated expectations have a strong causal effect on the expected outcome through the enactment of expectancy consistent behaviors (Rosenthal, 2002). The most relevant and studied parental expectations are concerned with the degree to which parents believe their children will succeed in school (Yamamoto \& Holloway, 2010), as well as the degree to which they believe their child will engage in risk behaviors (Nash, McQueen, \& Bray, 2005). These academic and behavioral parental expectations can be transmitted to adolescents through their influences on the parenting practices that promote academic engagement and discourage problem behavior (Eccles \& Wigfield, 2002). For instance, Halle, Kurtz-Costes, and Mahoney (1997) followed a group of low-income African American families and found that mothers' academic expectations predicted achievementrelated parenting behaviors and child math and reading achievement. A much larger study using the Panel Study of Income Dynamics data also found that parental educational expectations predicted a variety of parenting behaviors, such as parental warmth and creating a cognitively stimulating home environment (Davis-Kean, 2005). These behaviors subsequently predicted standardized achievement. These results held up separately for African Americans and European Americans. Other studies have also found that parents' behavioral expectations are predictors of their children's substance use (Simons-Morton, 2004) and engagement in risk behaviors (Nash et al., 2005).

It is also clear that African American parents do indeed have different expectations for their sons and daughters. In a longitudinal study, Graves (2008) found that African American parents began with equal expectations for boys and girls when they entered elementary school but their expectations decreased for boys by the time they entered third grade. Another study of African American students aged 6-16 years also found that parents had higher 
educational expectations for their daughters compared to their sons, even after prior achievement was controlled (Wood et al., 2007). They further concluded that parental expectations accounted for most of the reason girls had higher educational expectations than boys. Thus, African American parental expectations are strongly related to parental behaviors and their children's achievement and behavior. These parental expectations tend to be different for male and female children.

\section{The Current Study}

In summary, this study was designed to test the theoretical model in Figure 1 that suggests that African American mothers differentially socialize their sons and daughters because they expect their sons to face greater racial discrimination, which will lower mothers' beliefs in how well their sons will perform academically and increase their expectations of their sons' likelihood of engaging in problem behaviors. These expectations will then predict the type of parenting male and female adolescents receive. Mothers with higher academic expectations and lower risky behavior expectations for their adolescents will be more responsive and demanding, as well as report less conflict with their adolescent.

The sample was drawn from the Maryland Adolescent Development in Context Study (MADICS). The study was designed to examine how social contexts influence psychological factors that impact adolescents' developmental trajectories and behavioral choices (Eccles, 1997). The sample was unique and ideal for the purposes of the current study because it consisted of a large proportion of African American families from a socioeconomically and ecologically diverse county with rural, suburban, and urban settings. The data also included good measures of discrimination concerns, parental expectations, and parenting. In particular, adolescents and mothers were assessed on various parenting measures found to be different by gender in prior studies, such as behavioral control (e.g., monitoring and rule enforcement), responsiveness (e.g., communication, warmth, shared activities), and parent-child conflict.

In addition, factors such as family income can influence mothers' discrimination concerns, expectations for their children's future, and parenting practices. Income has been found to have important effects on family processes. According to the family stress model (McLoyd, 1990), economic disadvantage can increase mothers' psychological distress, which contributes to harsher parenting, subsequently impacting children's outcomes such as aca- demic achievement and mental health. In addition to the influence of income on parenting, African American mothers with higher income have also been found to perceive more racial discrimination than mothers with lower income (Lacy, 2007). These differences may be due to middle-class African Americans' increased exposure to interracial contexts, which increases their chances of experiencing racial discrimination.

In addition to income, mothers' education and age can also influence parenting. For instance, African American parents with more years of schooling have been found to have higher educational expectations and warmer relationships with their children, which led to higher child academic achievement (Davis-Kean, 2005; Halle et al., 1997). Maternal age may influence mothers' discrimination concerns as older parents may have experienced more overt racial discrimination. Therefore, these parental characteristics were statistically controlled in the analyses. In addition, adolescents' past standardized test scores were statistically controlled in the analyses due to the influence that students' past academic achievement can have on parents' expectations for the future (Yamamoto \& Holloway, 2010).

\section{Method}

\section{Participants}

Stratified sampling was used to proportionally represent families from each of the 23 junior high schools in one Maryland county. Out of the families asked to participate in the MADICS, 90\% of eligible families consented to participate. Of the 924 African American families in the MADICS, the current sample was limited to the 796 African American families consisting of a mother who completed the primary caregiver interview and self-administered survey and a seventh-grade adolescent who completed the child self-administered survey and interview in Wave 1 . The sample was diverse economically with the middle $50 \%$ of families having an income between $\$ 25,000$ and $\$ 64,999$ and $7.4 \%$ of families having a total income below $\$ 15,000$. Mothers on average were 37.92 years old and had 13.63 years of education. Over half of the mothers were married $(n=460)$, whereas 212 mothers were divorced or separated, 108 mothers were never married, and 15 mothers were widowed. A total of $81.8 \%$ of single mothers had income below the median of $\$ 40,000$, whereas $31.1 \%$ of married mothers had income below the median. The seventh graders ranged in age from 11 to 14 years 
with an average age of 12.21 years. Almost $52 \%$ of the adolescents were male $(n=413)$. Based on independent sample $t$ tests, the African American families included in the sample did not significantly differ from the 128 excluded African American families on family income, parental education, discrimination concerns, parental expectations, or the parenting variables used in this study.

\section{Measures}

Racial discrimination concerns. Mothers were asked two items on how much race would impact their children's future. These items were created for the MADICS and have been used previously to assess African American parents' perceptions of racial barriers and predict parenting practices and adolescents' academic achievement (Harris, 2011). "How much do you think people will discriminate against (child) because (he or she) is (race)," was measured on a scale from 1 (not at all) to 4 (a lot). "Do you think it will be harder for (child) to get ahead in life because (he or she) is (race)?" was measured on a scale from 1 (no) to 2 (yes). The coefficient alpha was .59.

Gender discrimination concerns. Mothers also answered two items about the effects of gender on their children's future: "Do you think (child) will be discriminated against because of (his or her) sex," and "Do you think it will be harder for (child) to get ahead in life because of (his or her) sex?" The items were created for the MADICS based on theoretical considerations and were measured on a 2-point scale from 1 (no) to 2 (yes). The coefficient alpha was .74.

Academic expectations. Academic expectations for the future were measured using three items that asked the primary caregiver what the chances were that her adolescent would: (a) complete college, (b) find a stable and well-paying job, and (c) do well in junior and senior high. All of the items were on a 5-point scale from 1 (very low) to 5 (very high). This scale was taken from previous work by Eccles and colleagues (Eccles Parsons et al., 1983). The coefficient alpha for academic expectations was .80 .

Behavioral expectations. Behavioral expectations for the future were measured using six items derived from previous work on expectancies by Eccles and colleagues (Eccles Parsons et al., 1983). The primary caregiver was asked what the chances were that her adolescent would: (a) use drugs, (b) have a drinking problem, (c) be held back a grade, (d) get in trouble with the police, (e) get involved with a gang, and (f) often cut school. All of the items were on a 5-point scale from 1 (very low) to 5 (very high). They were averaged and recoded so that higher numbers meant that parents had positive behavioral expectations for their adolescents. The coefficient alpha for behavioral expectations was .87 .

Democratic decision making. Democratic decision making was measured in the primary caregiver selfadministered surveys. Mothers were asked four items that were modified from the Epstein and McPartland (1977) Family Decision-Making Scale. The items were as follows: (a) "How often do you ask your 7th grader what (she or he) thinks before deciding on family matters that involve him or her?" (b) "How often do you ask your 7th grader what (she or he) thinks before making decisions that affect him or her?" (c) "I encourage my 7th grader to give his or her ideas and opinions even if we might disagree," and (d) "I find that listening to what my 7th grader has to say helps me reach a better decision." This scale used a 5-point scale from 1 (almost never) to 5 (almost always). The coefficient alpha was .74.

Shared activities. Shared activities were measured using five items from the primary caregiver selfadministered survey regarding how much time was spent with the seventh grader in various activities. These items were modified from the Philadelphia Family Management Study (Furstenberg, Cook, Eccles, Elder, \& Sameroff, 1999). Mothers were asked "How often have you...": (a) helped your seventh grader do homework or a school project, (b) done indoor activities with your seventh grader other than watching TV, (c) discussed your seventh grader's experiences at school with her (e.g., ask child what she or he did at school), (d) done something together just for fun (e.g., go to the movies, go for walks), and (e) discussed news or current events with your seventh grader? The scale was from 1 (never) to 5 (very often). The coefficient alpha was .79.

Communication. Parent-child communication was measured with six items in the primary caregiver self-administered surveys modified from the Philadelphia Family Management Study (Furstenberg et al., 1999). Each mother indicated how often she and her adolescent talked about various issues including: (a) what is going on in his or her life, (b) how things are going with his or her friends, (c) his or her plans for the future, (d) problems he or she is having at school, (e) future jobs he or she might have, and (f) what courses he or she should take in school and how these courses will prepare him or her for future jobs. The scale for the items was a 6-point scale from 1 (almost never) to 6 (almost every day). The coefficient alpha for primary caregivers was .84 . 
Conflict. Mothers answered four items in the self-administered surveys regarding conflict with their seventh grader beginning with the stem, "How often do you and your 7th grader disagree or argue about..." The items included: (a) how he or she spends money, (b) how he or she spends time outside school, (c) his or her report card, and (d) his or her clothes, hair, and makeup? These items were taken from the Philadelphia Family Management Study (Furstenberg et al., 1999) and were on a 5-point scale from 1 (almost never) to 5 (almost always). The coefficient alpha was .74.

Monitoring. Adolescents were asked seven items regarding how much their parents monitored them. The scale was created for the MADICS based on theoretical concerns and factor analyses and is similar to other measures of monitoring (Eccles, Early, Fraser, Belansky, \& McCarthy, 1997). These items included: (a) "My parents know where I am after school," (b) "My parent(s) know when I am having trouble with my homework," (c) "How often do your parents know who you are with when you are not at home?" (d) "How often do your parents know if you are home by the time you are supposed to be?" (e) "When your parents are not at home, do you know how to get in touch with them?" (f) "If your parents are not at home, do you leave a note or call them to let them know where you are going?" and (g) "How often would parent know if you broke these rules?" The items were on a scale from 1 (almost never) to 5 (almost always). The coefficient alpha was .67.

Rule enforcement. Adolescents were asked eight items about how much they had to follow various rules with the stem, "How often do you have to follow these rules: (a) when and how much television you can watch, (b) letting your family know where you're going when you go out, (c) who you go out with, (d) getting your homework done, (e) doing household chores, (f) what time you go to bed, (g) what time you come home after school, and (h) what time to be in on school nights." The items were modified from the Philadelphia Family Management Study (Furstenberg et al., 1999) and were on a scale from 1 (almost never) to 5 (almost always). The coefficient alpha was .67.

Background variables. Mother's age in years and number of years of education were measured using reports from the primary caregiver interview. Mothers also reported total family income on a scale from 1 (less than $\$ 5,000$ ) to 16 (more than $\$ 75,000$ ) with each number representing a range of $\$ 5,000$. Youth's standardized test scores from the fifthgrade administration of the California Achievement
Tests were used to control for previous achievement. Scores ranged from 360 to 645 .

\section{Analytic Plan}

Latent variable structural equation modeling (SEM) with maximum likelihood estimation was used to estimate the direct (nonmediated) and indirect (mediated) effects of gender on parenting practices through discrimination concerns and parental expectations as shown in Figure 1. Parcels were created for behavioral expectations, monitoring, and rule enforcement to reduce spurious covariation and increase the stability of the solution (Little, Cunningham, Shahar, \& Widaman, 2002). For behavioral expectations, the six items were distributed into three parcels that had factor loadings of $.74, .90$, and .87. For monitoring, the seven items were randomly distributed into three parcels with loadings of .68, .58, and .67. For rule enforcement, the eight items were randomly distributed into four parcels with loadings of .62, .55, .59, and .60. Democratic decision making, shared activities, and communication were used as indicators for the latent responsiveness variable.

The measurement models for discrimination concerns, expectations, and parenting were tested with exploratory factor analyses in IBM SPSS Statistics version 19 (IBM Corp., 2010) and then confirmatory factor analyses using SEM. Each factor had moderate to high reliabilities and the overall measurement model fit the data well, $\chi^{2}(242)=715.59, p<.001$, comparative fit index $(\mathrm{CFI})=.92$, root mean square error of approximation (RMSEA) $=.05$.

Mediation was assessed in two steps. First, it was established if gender had direct effects on discrimination concerns, expectations, and parenting practices. Next, we tested the full meditational model to determine whether discrimination concerns mediated the effects of gender on expectations and expectations mediated the effects of discrimination concerns on parenting practices. Bootstrap methods were used to estimate the biascorrected indirect effects (Arbuckle, 2007). Standard measures of model fit such as the CFI and the RMSEA were used to assess the model fit ( $\mathrm{Hu}$ \& Bentler, 1999).

In addition, an interaction term between racial and gender discrimination concerns was created by centering and multiplying composite measures of racial and gender discrimination concerns. A separate SEM was run with the interaction term included.

To be included in the study, participants had to participate in the Wave 1 survey and interview. 
Participants had to have information on gender and completed or almost completed their surveys with only a few skipped questions. Prior to imputation, most items had missing data for no more than 5\% of participants except for family income, which had $6.9 \%$ missing data. Missing data were imputed with the expectation maximization algorithm, which replaces missing values with iterative maximum likelihood estimations (Schafer, 1997).

\section{Results}

The bivariate correlations between the study variables and other descriptive statistics are presented in Table 1. Maternal income and education were positively associated with parental age, adolescents' past grades, responsiveness, monitoring, academic and behavioral expectations, and discrimination concerns. Parents with higher income and education also had less conflict with their adolescents. Higher past test scores were associated with more gender discrimination concerns as well as higher academic and behavioral expectations, less conflict, and more monitoring. Responsiveness, monitoring, rule enforcement, and academic and behavioral expectations were positively correlated with each other, but negatively associated with conflict. Results also showed that gender discrimination concerns were positively correlated with racial discrimination concerns. Racial discrimination concerns were negatively associated with behavioral expectations.
To examine the relations between child gender and the other study variables, an SEM with direct effects from gender to each of the study variables was conducted (see Table 2). As expected, girls and boys were significantly different on several parenting practices, expectations, and discrimination concerns. In particular, boys had less parental monitoring but higher levels of conflict than girls. They also had lower standardized test scores in fifth grade. Parents had higher academic and behavioral expectations and more gender discrimination concerns for girls than boys. There were no initial differences in responsiveness or parental background factors by gender.

\section{Structural Equation Model}

The full SEM as described above and illustrated in Figure 1 was then analyzed. Results showed that the model fit the data well, $\chi^{2}(316)=814.02$, $p<.001, \chi^{2} / d f=2.59$, Tucker-Lewis index (TLI) $=$ $.91, \mathrm{CFI}=.93$, RMSEA $<.05$. The model explained $18 \%$ of the variance in conflict, $10 \%$ in monitoring, $11 \%$ in responsiveness, and $5 \%$ in rule enforcement, as well as $34 \%$ of the variance in academic expectations and $11 \%$ of the variance in behavioral expectations. An examination of the specific paths showed that there were significant differences in discrimination concerns based on gender of the adolescent (see Figure 2). Mothers of sons were more concerned about racial discrimination impacting their adolescents' future than mothers of daughters. As expected, gender discrimination concerns

Table 1

Correlations Among Study Variables

\begin{tabular}{|c|c|c|c|c|c|c|c|c|c|c|c|c|}
\hline Variable & 1 & 2 & 3 & 4 & 5 & 6 & 7 & 8 & 9 & 10 & 11 & 12 \\
\hline 1. R. discrimination & - & & & & & & & & & & & \\
\hline 2. G. discrimination & $.31^{* * *}$ & - & & & & & & & & & & \\
\hline 3. A. expectations & -.02 & .06 & - & & & & & & & & & \\
\hline 4. B. expectations & $-.13^{* * *}$ & -.02 & $.55^{* * *}$ & - & & & & & & & & \\
\hline 5. Responsiveness & -.00 & .06 & $.23^{* * *}$ & $.17^{* * *}$ & - & & & & & & & \\
\hline 6. Monitoring & .02 & .06 & $.21^{* * *}$ & $.20^{* * *}$ & $.21^{* * *}$ & - & & & & & & \\
\hline 7. Conflict & -.02 & -.05 & $-.34^{* * *}$ & $-.31^{* * *}$ & $-.11^{* * *}$ & $-.18^{* * *}$ & - & & & & & \\
\hline 8. Rule enforcement & -.04 & .04 & $.13^{* * *}$ & $.09^{* *}$ & $.09 * *$ & $.45^{* * *}$ & $-.07^{*}$ & - & & & & \\
\hline 9. Fifth-grade test & $.11^{* *}$ & .08 & $.43^{* * *}$ & $.20^{* * *}$ & .05 & .07 & $-.29 * * *$ & .07 & - & & & \\
\hline 10. Parent age & $.19^{* * *}$ & $.10^{* *}$ & $.11^{* *}$ & .01 & .04 & .07 & -.06 & -.04 & $.22^{* * *}$ & - & & \\
\hline 11. Parent income & $.22^{* * *}$ & $.19^{* * *}$ & $.29^{* * *}$ & $.11^{* *}$ & $.09 * *$ & $.14^{* * *}$ & $-.16^{* * *}$ & -.02 & $.31^{* * *}$ & $.37^{* * *}$ & - & \\
\hline 12. Parent education & $.16^{* * *}$ & $.17^{* * *}$ & $.29^{* * *}$ & $.11^{* *}$ & $.13^{* * *}$ & $.10^{* *}$ & $-.11^{* *}$ & .00 & $.27^{* * *}$ & $.28^{* * *}$ & $.49^{* * *}$ & - \\
\hline$M$ & 1.91 & 1.25 & 3.98 & 3.87 & 3.85 & 4.09 & 2.21 & 4.31 & 480.13 & 37.92 & 9.54 & 13.62 \\
\hline$S D$ & 0.54 & 0.38 & 0.75 & 0.52 & 0.72 & 0.65 & 0.81 & 0.58 & 46.54 & 4.46 & 4.20 & 2.20 \\
\hline
\end{tabular}

Note. $N=796$ families. $\mathrm{R} .=$ racial; G. = gender; A. = academic; $\mathrm{B} .=$ behavioral . $* p<.05 . * * p .01 .{ }^{* * *} p<.001$. 
Table 2

Parameter Estimates and Significance Levels for Direct Effects of Gender on Discrimination Concerns, Expectations, and Parenting Practices Controlling for Background Factors

\begin{tabular}{lccr}
\hline & \multicolumn{3}{c}{ Direct effects } \\
\cline { 2 - 4 } & $b$ & $S E$ & $\beta$ \\
\hline Female $\rightarrow$ R. discrimination & $-.08^{* *}$ & .03 & -.12 \\
Female $\rightarrow$ G. discrimination & $.18^{* * *}$ & .03 & .23 \\
Female $\rightarrow$ A. expectations & $.11^{*}$ & .06 & .07 \\
Female $\rightarrow$ B. expectations & $.16^{* * *}$ & .04 & .16 \\
Female $\rightarrow$ Responsiveness & .01 & .07 & .01 \\
Female $\rightarrow$ Conflict & $-.14^{*}$ & .06 & -.10 \\
Female $\rightarrow$ Rule enforce & .10 & .05 & .08 \\
Female $\rightarrow$ Monitoring & $.24^{* * *}$ & .05 & .20 \\
\hline
\end{tabular}

Note. $N=796$ families. Adolescent's fifth-grade standardized test scores, mother's age, mother's education, and family income are controlled for but not shown. R. = racial; G. = gender; A. = academic; B. = behavioral.

${ }^{*} p<.05 .{ }^{* *} p<.01 . * * * p<.001$.

were much higher among mothers of daughters than mothers of sons. Discrimination concerns in turn had significant effects on parental expectations. As predicted, mothers with higher racial discrimination concerns had lower expectations for their adolescents' academic success and behavior. In contrast, gender discrimination concerns were not significantly related to mothers' expectations for their adolescents. Expectations were related to parenting practices. Parents with higher academic and behavioral expectations reported higher levels of monitoring and less conflict with their children. High academic expectations were also positively associated with responsiveness and rule enforcement.

There were also some significant indirect effects (see Table 3). First, gender had significant indirect effects on academic and behavioral expectations. Considering that only racial discrimination concerns had a significant effect on expectations, this finding suggests that adolescents' gender influences mothers' expectations through its effects on racial discrimination concerns. Racial discrimination concerns also had significant indirect effects on conflict, rule enforcement, monitoring, and responsiveness, which indicated that maternal expectations mediated the effects of racial discrimination concerns on parenting practices. Finally, there were significant indirect effects of gender on parenting practices. Being a girl indirectly led to higher levels of responsiveness, rule enforcement, and monitoring and lower levels of conflict through mothers' discrimination concerns and expectations.

A separate SEM with an interaction between racial discrimination concerns and gender discrimination concerns was also tested. The model fit the data well, $\chi^{2}(270)=685.15, p<.001, \chi^{2} / d f=2.54$, $\mathrm{TLI}=.91, \mathrm{CFI}=.93, \mathrm{RMSEA}<.05$, but there were

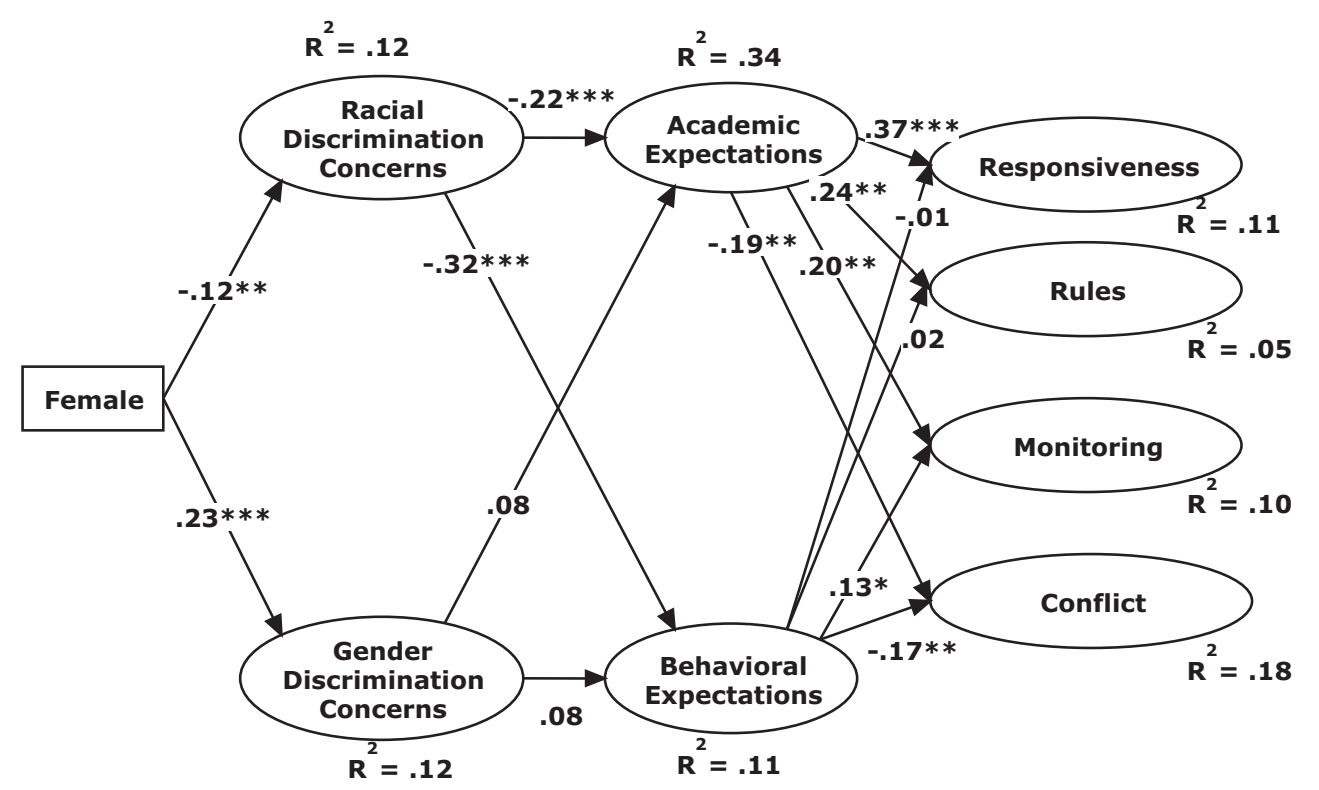

Figure 2. Standardized direct effects of gender, discrimination concerns, and parental expectations on parenting practices. Family income, maternal age, maternal education, and adolescents' fifth-grade test scores are controlled in the model. $\chi^{2}(316)=814.02$, $p<.001, \mathrm{CFI}=.93$, RMSEA $<.05$. ${ }^{*} p<.05 .{ }^{* *} p<.01 .{ }^{* * *} p<.001$. 
Table 3

Parameter Estimates and Significance Levels for Indirect Effects

\begin{tabular}{lrrr}
\hline & \multicolumn{3}{c}{ Indirect effects } \\
\cline { 2 - 5 } & $b$ & $S E$ & $\beta$ \\
\hline Female $\rightarrow$ Academic expectations & $.07^{*}$ & .03 & .04 \\
Female $\rightarrow$ Behavioral expectations & $.06^{*}$ & .03 & .06 \\
Female $\rightarrow$ Responsiveness & $.03^{*}$ & .01 & .02 \\
Female $\rightarrow$ Rule enforce & $.01^{*}$ & .01 & .01 \\
Female $\rightarrow$ Conflict & $-.03^{* *}$ & .01 & -.02 \\
Female $\rightarrow$ Monitoring & $.02^{*}$ & .01 & .02 \\
Racial discrimination $\rightarrow$ Responsiveness & $-.19^{*}$ & .07 & -.08 \\
Racial discrimination $\rightarrow$ Rule enforce & $-.11^{* *}$ & .05 & -.06 \\
Racial discrimination $\rightarrow$ Conflict & $.21^{* *}$ & .07 & .10 \\
Racial discrimination $\rightarrow$ Monitoring & $-.16^{* *}$ & .06 & -.08 \\
Gender discrimination $\rightarrow$ Responsiveness & .06 & .05 & .03 \\
Gender discrimination $\rightarrow$ Rule enforce & .03 & .03 & .02 \\
Gender discrimination $\rightarrow$ Conflict & -.05 & .04 & -.03 \\
Gender discrimination $\rightarrow$ Monitoring & .04 & .03 & .03 \\
\hline
\end{tabular}

Note. $N=796$ families. Adolescent's fifth-grade standardized test scores, mother's age, mother's education, and family income are controlled for but not shown. The standard errors and $p$ values are bias corrected and were estimated with 2,000 bootstrap samples in Amos 16.0.

$* p<.05 . * * p<.01$.

no significant relations between the interaction term and parental expectations.

\section{Discussion}

The purpose of this study was to better understand the psychosocial factors that explain why African American male and female youth are socialized differently. We tested a theoretical model that argued that African American mothers' concerns about racial and gender discrimination influence the academic and behavioral expectations they will have for their sons and daughters. In particular, we expected that mothers would be more concerned with racial discrimination for their sons and more concerned with gender discrimination for their daughters. We further expected those mothers with higher racial discrimination concerns to have lower expectations for their children's academic success and behavior. The model hypothesized that academic and behavioral expectations would predict the nature of the socialization males and females experienced. The overall model fit the data well and explained most of the differences in socialization experiences between African American male and female youth.

As predicted by the model and found by prior studies, there were significant and relatively large initial differences in the nature of parenting practices experienced by male and female adolescents. The girls were much higher on measures of parental monitoring and rule enforcement than the boys. The mothers of girls also reported less conflict in their parent-child relationship than did mothers of sons. These findings of parenting differences are not surprising and have been found in several studies with European American and African American samples (Hill \& Zimmerman, 1995; Mandara et al., 2010; Raley \& Bianchi, 2006). The more important question for the current study was if these gendered socialization patterns could be explained by mothers' discrimination concerns and expectations.

We argued that the history of racism and current social perceptions of limited academic and economic opportunities for African American males would lead mothers to be more concerned with the effects of racism for their sons than they were for their daughters. Considering the history of gender inequities in the United States, particularly in the economic sector, we also expected mothers' gender discrimination concerns to be influenced by the gender of their adolescents. Both hypotheses were supported, but the differences were not the same. Although mothers of sons reported slightly higher levels of racial discrimination concerns, the difference was not very large. Contrary to male adolescents' own reports of gender discrimination (Cogburn et al., 2011), mothers tended to have much higher levels of gender discrimination concerns for their daughters than their sons. This finding might be related to mothers' own experiences of discrimination based on gender. Because they may have personal experiences with gender discrimination, they may be more concerned about their daughters having similar experiences. Also, it is possible that even though gender clearly shapes mothers' concerns about racial discrimination, when asked about gender discrimination they are more used to thinking about it in terms of sexism toward females. Research examining fathers' discrimination concerns can also shed light onto whether these concerns are the same for mothers and fathers. In addition, parental reports on how the combination of race and gender influences their concerns about their adolescents' futures could provide more information in the future regarding how parents think about interactions between race and gender.

Racial discrimination concerns had very strong effects on maternal academic and behavioral expectations. As predicted, mothers with more concerns about racial discrimination had lower academic and behavioral expectations of their children. Counter to 
this finding, gender discrimination concerns had no relation with parental expectations. Mothers associated gender discrimination as more targeted toward females. Perhaps the growing gap between African American males' and females' success in school and the workforce makes mothers believe that gender discrimination is less influential to their daughters than racial discrimination is to their sons. As suggested before, this finding may also imply that mothers feel that their daughters have the capacity to overcome whatever gender-based discrimination they will encounter. In contrast, mothers may believe that racial discrimination is more difficult to overcome than gender discrimination. Mothers may be concerned about the impacts of unfair disciplinary strategies, police surveillance, and other discriminatory practices having more disruptive effects on boys' education and advancement.

In addition, more distal concerns related to employment may influence mothers' concerns, expectations, and parenting practices. African American men are more likely to face unemployment and underemployment than African American women due to the shift in the economy away from manufacturing (Wilson, 2011). This economic reality may also help explain why the relations between racial discrimination concerns and expectations were significant whereas gender discrimination concerns were not related to expectations. Parents may base their expectations for sons partly on their perceptions of the current economic and racial climate, which may appear to favor women.

As hypothesized, mothers of sons initially had lower expectations of academic success and prosocial behavior for their sons than did mothers of daughters. This finding replicates past studies that found African American parents to have higher expectations for girls than boys (Wood et al., 2007). Furthermore, as proposed in the model, the effects of gender on maternal expectations were largely explained by mothers' discrimination concerns. Mothers had lower expectations for their sons' academic and professional futures than for their daughters, and the data supported our hypothesis that this is due to greater concerns about racial discrimination negatively impacting their sons' futures. The relation indicates that although there may be causes of differential socialization in common with European Americans, there are unique contextual factors that influence African American mothers' cognitions and practices, as suggested in the integrative model of minority child development (Garcia Coll et al., 1996).

There were also strong links between expectations and parenting practices. Mothers with higher academic and behavioral expectations reported less conflict with their children. In addition, mothers with higher academic expectations reported more responsiveness in their parenting. These findings could be explained by parental investment theory, which suggests that parents will put more of their limited resources, such as time and energy, into the children that they believe are more likely to succeed academically or professionally in the future (Hertwig, Davis, \& Sulloway, 2002). In this case, mothers appear to spend more time communicating and participating in activities with their adolescents, as well as allowing them to participate more in family decisions. It is also possible that there are other adolescent characteristics that contribute both to mothers' higher levels of expectations and responsiveness, as well as lower levels of conflict. Past studies have found links between adolescent temperamental characteristics, parental expectations, and parent-adolescent conflict (Dekovic, Noom, \& Meeus, 1997). In addition, African American mothers of young children have indicated being more concerned about their sons being manageable by other caregivers and about them getting into trouble due to their higher levels of physical activity (Tamis-Lemonda et al., 2009). These concerns related to manageability could translate into lower academic and behavioral expectations, as well as different parenting practices.

In addition, there was significant mediation of the relations between racial discrimination concerns and parenting practices through maternal expectations. This finding indicates that mothers who believe that their adolescents' futures will be adversely impacted by racial discrimination, parent them differently due to the mothers' lowered academic and behavioral expectations for their adolescents. Thus, the opportunities that mothers perceive as available to their children can influence their expectations and parenting. A lack of perceived opportunities might lead mothers to change their goals and prepare their children for different roles than they would if they believed that there were fewer barriers. However, expectations did not mediate the relation between gender discrimination concerns and parenting practices. This implies that there are other factors that influence how much discrimination concerns influence parenting. More study is necessary to understand why the type of discrimination matters in relation to expectations and parenting.

There were other interesting findings not directly related to the key study questions. Older mothers had more concerns about the influence of racial discrimination on their children. This relation is most 
likely due to parents' own experiences growing up with greater discrimination (Thornton, Chatters, Taylor, \& Allen, 1990). Another interesting finding was that mothers with higher income, but not more education, had more concerns about racial and gender discrimination negatively influencing their children's future. This finding also corresponds to previous research that found that African Americans with higher SES had more perceptions of experiencing overt racism than African Americans with lower SES (Lacy, 2007). Perhaps higher income African American mothers are in more interracial contexts and have had more experiences of racial discrimination or hostility than lower income mothers who are more likely to live in predominately African American neighborhoods (Alba, Logan, \& Stults, 2000). Their children may also be more likely to attend predominately European American or diverse schools, which also may heighten concerns of racial discrimination. Given the importance of discrimination concerns for African American mothers' expectations and parenting, untangling the relation between such concerns and SES is another fruitful avenue for future studies.

These findings must be interpreted in light of a few limitations. First, because the data are correlational, it is possible that there are additional variables that cause the differences found in parenting and expectations. Adolescents' previous behavior in particular could be responsible for parents' attitudes, beliefs, and practices (Yamamoto \& Holloway, 2010). However, the fact that gender differences were found even after controlling for previous academic achievement suggests that mothers' discrimination concerns, expectations, and parenting are not solely a function of adolescents' past behavior. In addition, other factors might influence the relation between discrimination concerns and parenting. For instance, it is possible that some parents might heighten their expectations in the face of racial barriers so that their children are more prepared to succeed when they experience discrimination (Bowman \& Howard, 1985). Examining protective factors such as parents' racial identity, self-efficacy, and other characteristics in future research will be important to broadening our understanding of the role of discrimination in African American families and sources of intragroup variation in these relations.

An additional limitation is that the data do not come from a nationally representative sample, so the findings may not be generalizable to the U.S. population of African Americans. In this regard, one clear strength of the study is that the sample included a high percentage of middle-class African Americans. Almost all past research on African American differential socialization has focused primarily on low-income and single-mother-headed families (Hill \& Zimmerman, 1995; Wood et al., 2007).

Finally, some of the parenting measures were composed from a few items and have lower than optimal reliabilities. This measurement issue is a problem found in many parenting studies (Sabatelli \& Bartle, 1995). Although SEM helps account for measurement error, it is possible that the analyses underestimate the relations among parental concerns, parental expectations, and parenting practices. In addition, common method variance could inflate or deflate the estimates of the relations examined. While both adolescents and mothers reported parenting practices, discrimination concerns and expectations were based on mothers' self-reports and could be correlated due to the mothers' affect or due to biases in the instruments used. However, the finding that high gender discrimination concerns were not related to expectations suggests that the relations found for racial discrimination are not simply due to underlying personality traits or other sources.

Despite these limitations, this study had several implications for research and practice. This study provided evidence that African American mothers' concerns about the effects of discrimination on their adolescents' future differ based on their adolescents' gender. These concerns about discrimination in turn influence their academic and behavioral expectations and parenting practices. This finding is of great concern due to the relations found between maternal expectations and practices and subsequent adolescent outcomes, including academic achievement and risk behaviors (Mandara et al., 2010). The findings also demonstrate one unique pathway through which differential socialization occurs in African American families. This research provides further support that the history of social stratification and discrimination experiences of African Americans in the United States has long-lasting implications for the development of African American children and the childrearing practices of their parents. The social contexts in which families are situated influence the beliefs and practices of parents. Future work should continue to examine how perceived opportunity structures influence African American parents' and adolescents' beliefs and behaviors and should build upon ecological models that emphasize the importance of social position and stratification in minority child development (Garcia Coll et al., 1996; Spencer et al., 1997). 
In addition, the knowledge that racial discrimination concerns are associated with lower parental expectations and influence parenting practices can help inform interventions for parents, teachers, and schools. Parenting interventions can make parents aware of this relation and discuss methods to socialize children to face potential obstacles related to discrimination without lowering expectations. Also, it is important for teachers and school administrators to be aware of the possible pernicious effects of racial discrimination concerns on expectations. Creating school and classroom environments that make both parents and students of various ethnicities and both genders feel welcomed may lower concerns about racial discrimination and benefit students through its impact on parents' expectations and parenting practices.

\section{References}

Alba, R. D., Logan, J. R., \& Stults, B. J. (2000). How segregated are middle-class African Americans? Social Problems, 47, 542-558. doi:10.2307/3097134

Arbuckle, J. L. (2007). Amos 16.0 user's guide. Spring House, PA: Amos Development.

Bean, R. A., Barber, B. K., \& Crane, D. (2006). Parental support, behavioral control, and psychological control among African American youth-The relationships to academic grades, delinquency, and depression. Journal of Family Issues, 27, 1335-1355. doi:10.1177/0192513X06289649

Bettencourt, B. A., \& Miller, N. (1996). Gender differences in aggression as a function of provocation: A meta-analysis. Psychological Bulletin, 119, 422-447. doi:10.1037/ 0033-2909.119.3.422

Bowman, P. J., \& Howard, C. (1985). Race-related socialization, motivation and academic achievement: A study of Black youths in three-generation families. Journal of American Academy of Child Psychiatry, 24, 134-141. doi:10.1016/S0002-7138(09)60438-6

Burchinal, M. R., Roberts, J. E., Zeisel, S. A., \& Rowley, S. J. (2008). Social risk and protective factors for African American children's academic achievement and adjustment during the transition to middle school. Developmental Psychology, 44, 286-292. doi:10.1037/0012-1649.44.1.286

Cauce, A. M., Hiraga, Y., Graves, D., Gonzales, N., RyanFinn, K., \& Grove, K. (1996). African American mothers and their adolescent daughters: Closeness, conflict, and control. In N. Way (Ed.), Urban girls: Resisting stereotypes, creating identities (pp. 100-116). New York: NYU Press.

Chavous, T. M., Rivas-Drake, D., Smalls, C., Griffin, T., \& Cogburn, C. (2008). Gender matters, too: The influences of school racial discrimination and racial identity on academic engagement outcomes among African American adolescents. Developmental Psychology, 44, 637-654. doi:10.1037/0012-1649.44.3.637
Cogburn, C. D., Chavous, T. M., \& Griffin, T. M. (2011). School-based racial and gender discrimination among african american adolescents: Exploring gender variation in frequency and implications for adjustment. Race and Social Problems, 3, 25-37. doi:10.1007/s12552-0119040-8

Cunningham, M., Swanson, D. P., Spencer, M. B., \& Dupree, D. (2003). The association of physical maturation with family hassles among African American adolescent males. Cultural Diversity and Ethnic Minority Psychology, 9, 276-288. doi:10.1037/1099-9809.9.3.276

Davis-Kean, P. E. (2005). The influence of parent education and family income on child achievement: The indirect role of parental expectations and the home environment. Journal of Family Psychology, 19, 294-304. doi:10.1037/0893-3200.19.2.294

Dekovic, M., Noom, M. J., \& Meeus, W. (1997). Expectations regarding development during adolescence: Parental and adolescent perceptions. Journal of Youth and Adolescence, 26, 253-272. doi:10.1007/s10964-0050001-7

Eccles, J. S. (1997). MADICS study of adolescent development in multiple contexts, 1991-1998, Murray Research Archive [Distributor]. Retrieved August 28, 2009, from http://hdl. handle.net/1902.1/01066UNF:3:pRf0kEYV4gNpDP4Wtds $8 \mathrm{Fw}==$

Eccles, J. S., Early, D., Fraser, K., Belansky, E., \& McCarthy, K. (1997). The relation of connection, regulation, and support for autonomy to adolescents' functioning. Journal of Adolescent Research, 12, 263-286. doi:10.1177/ 0743554897122007

Eccles Parsons, J. S., Adler, T. F., Futterman, R., Goff, S. B., Kaczala, C. M., Meece, J. L., et al. (1983). Expectancies, values and academic behaviors. In J. T. Spence (Ed.), The development of achievement motivation (pp. 283331). Greenwich, CT: JAI.

Eccles, J. S., \& Wigfield, A. (2002). Motivational beliefs, values, and goals. Annual Review of Psychology, 53, 109132. doi:10.1146/annurev.psych.53.100901.135153

Epstein, J. L., \& McPartland, J. M. (1977). Family and school interactions and main effects on affective outcomes (Report No 235). Baltimore, MD: Johns Hopkins University, Center for Social Organization of Schools.

Furstenberg, F. F., Cook, T., Eccles, J., Elder, G. H., \& Sameroff, A. (1999). Managing to make it: Urban families in highrisk neighborhoods. Chicago: University of Chicago Press.

Garcia Coll, C., Crnic, K., Lamberty, G., Wasik, B. H., Jenkins, R., \& García, H. V., et al. (1996). An integrative model for the study of developmental competencies in minority children. Child Development, 67, 1891-1914. doi:10.1111/j.1467-624.1996.tb01834.x

Graves, S. (2008). Are we neglecting African American males: Parental involvement differences between African American males and females during elementary school? Journal of African American Studies, 14, 263-276. doi:10.1007/s12111-008-9065-2

Halle, T. G., Kurtz-Costes, B., \& Mahoney, J. L. (1997). Family influences on school achievement in low- 
income, African American children. Journal of Educational Psychology, 89, 527-537. doi:10.1037/0022-0663. 89.3.527

Harris, A. (2011). Kids don't want to fail. Cambridge, MA: Harvard University Press.

Hertwig, R., Davis, J. N., \& Sulloway, F. J. (2002). Parental investment: How an equity motive can produce inequality. Psychological Bulletin, 12, 728-745. doi:10.1037/ 0033-2909.128.5.728

Hill, N. E., Ramirez, C., \& Dumka, L. E. (2003). Early adolescents' career aspirations: A qualitative study of perceived barriers and family support among lowincome, ethnically diverse adolescents. Journal of Family Issues, 24, 934-959.

Hill, S. A. (2002). Teaching and doing gender. Sex Roles, 47, 493-504.

Hill, S. A., \& Zimmerman, M. K. (1995). Valiant girls and vulnerable boys: The impact of gender and race on mothers' caregiving for chronically ill children. Journal of Marriage and the Family, 57, 43-53.

Hu, L., \& Bentler, P. M. (1999). Cutoff criteria for fit indexes in covariance structure analysis: Conventional criteria versus new alternatives. Structural Equation Modeling, 6, 1-55.

Hudley, C., \& Graham, S. (2001). Stereotypes of achievement striving among early adolescents. Social Psychology of Education, 5, 201-224.

IBM Corp. (2010). IBM SPSS statistics for Windows, version 19.0 [Computer software]. Armonk, NY: Author.

Irving, M. A., \& Hudley, C. (2005). Cultural mistrust, academic outcome expectations, and outcome values among African American adolescent men. Urban Education, 40, 476-496.

Klonoff, E. A., \& Landrine, H. (1995). The schedule of sexist events. Psychology of Women Quarterly, 19, 439470. doi:10.1111/j.1471-6402.1995.tb00086.x

Klonoff, E. A., Landrine, H., \& Campbell, R. (2000). Sexist discrimination may account for well-known gender differences in psychiatric symptoms. Psychology of Women Quarterly, 24, 93-99. doi:10.1111/j.1471-6402.2000.tb01025.x

Lacy, K. (2007). Blue-Chip Black: Race, class, and status in the new Black middle class. Berkeley: University of California Press.

Levin, S., Sinclair, S., Veniegas, R., \& Taylor, P. (2002). Perceived discrimination in the context of multiple social identities. Psychological Science, 13, 557-560. doi:10.1111/1467-9280.00498

Little, T. D., Cunningham, W. A., Shahar, G., \& Widaman, K. F. (2002). To parcel or not to parcel: Exploring the question, weighing the merits. Structural Equation Modeling, 9, 151-173. doi:10.1207/S15328007SEM0902_1

Mandara, J. (2006). The impact of family functioning on African American males' academic achievement: A review and clarification of the empirical literature. Teachers College Record, 108, 206-223. doi:10.1111/j.14679620.2006.00648.x

Mandara, J., \& Pikes, C. L. (2008). Guilt trips and love withdrawal: Does mothers' use of psychological control predict depressive symptoms among African American adolescents? Family Relations, 57, 602-612. doi:10.1111/j. 1741-3729.2008.00526.x

Mandara, J., Varner, F., \& Richman, S. (2010). Do African American mothers really "love" their sons and "raise" their daughters? Journal of Family Psychology, 24, 41-50. doi: $10.1037 / \mathrm{a} 0018072$

McLoyd, V. C. (1990). The impact of economic hardship on Black families and children: Psychological distress, parenting, and socioemotional development. Child Development, 61, 311-346. doi:10.1111/j.1467-8624.1990. tb02781.x

Nash, S. G., McQueen, A., \& Bray, J. H. (2005). Pathways to adolescent alcohol use: Family environment, peer influence, and parental expectations. Journal of Adolescent Health, 37, 19-28. doi:10.1016/j.jadohealth. 2004.06.004

Neal, L. V. I., McCray, A. D., Webb-Johnson, G., \& Bridgest, S. T. (2003). The effects of African American movement styles on teachers' perceptions and reactions. Journal of Special Education, 37, 49-57. doi:10. $1177 / 00224669030370010501$

Organisation for Economic Co-operation and Development. (2005). The measurement of scientific and technological activities: Guidelines for collecting and interpreting innovation data: Oslo manual (3rd ed.). Paris: Author.

Pettit, G. S., Laird, R. D., Dodge, K. A., Bates, J. E., \& Criss, M. M. (2001). Antecedents and behavior-problem outcomes of parental monitoring and psychological control in early adolescence. Child Development, 72, 583598. doi:10.1111/1467-8624.00298

Raley, S., \& Bianchi, S. (2006). Sons, daughters, and family processes: Does gender of children matter? Annual Review of Sociology, 32, 401-421. doi:10.1146/annurev. soc.32.061604.123106

Richards, M. H., Miller, B. V., O’Donnell, P. C., Wasserman, M. S., \& Colder, C. (2004). Parental monitoring mediates the effects of age and sex on problem behaviors among African American urban young adolescents. Journal of Youth and Adolescence, 33, 221-233. doi:10. 1023/B:JOYO.0000025321.27416.f6

Rosenthal, R. (2002). Covert communication in classrooms, clinics, courtrooms, and cubicles. American Psychologist, 57, 839-849. doi:10.1037/0003-066X.57.11.839

Sabatelli, R. M., \& Bartle, S. E. (1995). Survey approaches to the assessment of family functioning: Conceptual, operational, and analytical issues. Journal of Marriage and the Family, 57, 1025-1039. doi:10.2307/353420

Saunders, J., Davis, L., Williams, T., \& Williams, J. H. (2004). Gender differences in self-perceptions and academic outcomes: A study of African American high school students. Journal of Youth and Adolescence, 33, 81-90. doi:10.1023/ A:1027390531768

Schafer, J. L. (1997). Analysis of incomplete multivariate data. Boca Raton, FL: Chapman and Hall/CRC.

Seaton, E. K., Caldwell, C. H., Sellers, R. M., \& Jackson, J. S. (2008). The prevalence of perceived discrimination among African American and Caribbean Black youth. 
Developmental Psychology, 44, 1288-1297. doi:10.1037/ a0012747

Sharp, E., \& Ispa, J. (2009). Inner-city single Black mothers' gender-related childrearing expectations and goals. Sex Roles, 60, 656-668. doi:10.1007/s11199-008-9567-3

Sidanius, J., Pratto, F., van Laar, C., \& Levin, S. (2004). Social dominance theory: Its agenda and method. Political Psychology, 25, 845-880. doi:10.1111/j.1467-9221.2004.00401.x

Simons-Morton, B. (2004). Prospective association of peer influence, school engagement, drinking expectancies, and parent expectations with drinking initiation among sixth graders. Addictive Behaviors, 29, 299-309. doi:10. 1016/j.addbeh.2003.08.005

Smetana, J. G. (2000). Middle-class African American adolescents' and parents' conceptions of parental authority and parenting practices: A longitudinal investigation. Child Development, 71, 1672-1686. doi:10.1111/14678624.00257

Smetana, J., \& Gaines, C. (1999). Adolescent-parent conflict in middle-class African American families. Child Development, 70, 1447-1463. doi:10.1111/1467-8624.00105

Snyder, T. D., \& Dillow, S. A. (2007). Digest of educational statistics 2006. Washington, DC: National Center for Educational Statistics.

Spencer, M. B., Dupree, D., \& Hartmann, T. (1997). A phenomenological variant of ecological systems theory (PVEST): A self-organization perspective in context. Development and Psychopathology, 9, 817-833.

Stevenson, H. C. (1997). Missed, dissed, and pissed: Making meaning of neighborhood risk, fear, and anger management in urban Black youth. Cultural Diversity and Mental Health, 3, 37-52. doi:10.1037/1099-9809.3.1.37

Stevenson, H. C., McNeil, J. D., Herrero-Taylor, H., \& Davis, G. Y. (2005). Influence of perceived neighbor- hood diversity and racism experience on the racial socialization of Black youth. Journal of Black Psychology, 31, 273-290. doi:10.1177/0095798405278453

Swanson, D. P., Cunningham, M., \& Spencer, M. B. (2003). Black males' structural conditions, achievement patterns, normative needs, and "opportunities." Urban Education, 38, 608-633. doi:10.1177/0042085903256218

Tamis-Lemonda, C. S., Briggs, R. D., McClowry, S. G., \& Snow, D. L. (2009). Maternal control and sensitivity, child gender, and maternal education in relation to children's behavioral outcomes in African American families. Journal of Applied Developmental Psychology, 30, 321-331. doi:10.1016/j.appdev.2008.12.018

Thomas, D. E., \& Stevenson, H. (2009). Gender risks and education: The particular classroom challenges for urban low-income African American boys. Review of Research in Education, 33, 160-180. doi:10.3102/ 0091732 X08327164

Thornton, M. C., Chatters, L. M., Taylor, R. J., \& Allen, W. R. (1990). Sociodemographic and environmental correlates of racial socialization by Black parents. Child Development, 61, 401-409. doi:10.1111/j.1467-8624.1990. tb02786.x

Wilson, W. J. (2011). When work disappears: The world of the new urban poor. New York: Random House Digital.

Wood, D., Kaplan, R., \& Mcloyd, V. C. (2007). Gender differences in the educational expectations of urban, low-income African American youth: The role of parents and the school. Journal of Youth and Adolescence, 36, 417-427. doi:10.1007/s10964-007-9186-2

Yamamoto, Y., \& Holloway, S. D. (2010). Parental expectations and children's academic performance in sociocultural context. Educational Psychology Review, 22, 189-214. doi:10.1007/s10648-010-9121-z 